ASTHMA

\title{
Soluble CD86 protein in serum samples of patients with asthma
}

\author{
H-Z Shi, Z-F Xie, J-M Deng, Y-Q Chen, C-Q Xiao
}

Thorax 2004;59:870-875. doi: 10.1136/thx.2004.021840

See end of article for authors' affiliations

....................

Correspondence to: Dr H-Z Shi, Departments of Respiratory and Critical Care Medicine, First Affiliated Hospital, Guangxi Medical University, Nanning 530021, Guangxi, People's Republic of China; hzshi@163.net or hzshi@public.nn.gx.cn

Received 27 January 2004 Accepted 24 June 2004
Background: Previous studies have reported that soluble (s) CD86 is involved in the initiation of the immune response. A study was undertaken to investigate the concentrations of sCD86 in serum samples from patients with bronchial asthma and to determine the cell origin of sCD86.

Methods: Serum sCD86 concentrations were measured in 52 asthmatic subjects and 25 non-atopic normal volunteers using an enzyme linked immunosorbent assay, and the relationship of serum sCD86 concentrations to asthma severity and to total and differential white cell counts was analysed. Each type of white blood cell was purified and cultured in vitro to determine the cell origin of serum sCD86.

Results: Serum samples from patients with an acute asthma exacerbation had much higher levels of sCD86 $(585.4(20.5) \mathrm{lU} / \mathrm{ml})$ than those from stable asthmatics $(479.6(15.7) \mathrm{IU} / \mathrm{ml}, \mathrm{p}<0.001)$ and healthy individuals (435.1 (13.8) IU/ml, $<<0.001)$, and there was no difference between the latter two groups $(p=0.079)$. In asthmatic subjects the serum sCD86 level was inversely correlated with airway responsiveness, forced expiratory volume in 1 second, and with arterial carbon dioxide tension. In addition, the serum sCD86 level was positively correlated with numbers of lymphocytes, eosinophils, monocytes, but not neutrophils. The in vitro experiments indicated that sCD86 was produced by monocytes.

Conclusions: The serum sCD86 protein level was significantly increased in asthmatic subjects during an exacerbation and correlated with the severity of asthma. SCD86 is most probably derived from monocytes in the peripheral blood.
$\mathrm{N}$ aïve $\mathrm{T}$ lymphocytes require two distinct signals from antigen-presenting cells (APC) to be functionally activated..$^{12}$ The first signal, which confers specificity, is provided by the interaction of the T cell receptor with major histocompatibility complex II complexes on APCs. A second co-stimulatory signal can be provided by APC borne ligands for the CD28 and cytotoxic lymphocyte associated antigen-4 (CTLA-4) receptors on $\mathrm{T}$ cells. CD28 is constitutively expressed by $\mathrm{T}$ cells and interacts with the $\mathrm{B} 7$ molecules B7-1 (CD80) and B7-2 (CD86). ${ }^{3}$ CD80 and CD86 are capable of forming homodimers, allowing for interactions with homodimers of either CD28 or CTLA-4. The interaction of CD28 with its ligands is weaker than the interaction with CTLA-4. Human CD80 binds to human CTLA-4 and CD28 with $\mathrm{Kd}$ values of 0.42 and $4 \mu \mathrm{M}$, respectively, for the monomeric interactions. ${ }^{5}$ The CD86:CTLA-4 interaction is of an affinity similar to CD80:CD28 and the CD28:CD86 interaction is of even lower affinity. ${ }^{6}$ CD80 and CD86 are type 1 membrane glycoproteins belonging to the immunoglobulin (Ig) supergene family. Despite having the same ligands, CD80 and CD86 appear to be involved in different mechanisms; CD80 can be more potent than CD86 in inducing an antitumoral response while CD86 preferentially induces the production of a helper (Th) 2 response. ${ }^{78}$ Due to its constitutive expression on human APCs, it has been suggested that CD86 may be involved in the initiation of the immune response.

Allergic asthma is a disease characterised by airway hyperresponsiveness, pulmonary inflammation, and raised serum IgE levels. Production of Th2 cytokines such as interleukin (IL)-4, IL-5 and IL-13 in allergic asthma is at least partly responsible for eliciting the cardinal pathogenic changes of the asthmatic phenotype. ${ }^{9}$ The factors in asthma that govern the production of Th2 cytokines over Thl cytokines, such as interferon- $\gamma$, are slowly being revealed.
One likely factor is the cytokine profile of $\mathrm{T}$ cells which is influenced by APCs, possibly through co-stimulatory signals. Such signals may be provided by ligation of CD28 or CTLA-4 with CD80 or CD86. ${ }^{10}$ Jeannin and coworkers have reported that soluble (s) CD86 results from an alternatively spliced transcript characterised by the deletion of the transmembrane domain; and that SCD86 provides a co-stimulatory signal to memory human T cells. ${ }^{11}$ Circulating sCD86 has been reported to be detected in the plasma of normal individuals and patients with leukaemia. ${ }^{12}$ Reverse transcriptase polymerase chain reaction analysis has shown that the transcript for sCD86 is expressed in normal monocytes, dendritic cells, as well as some leukaemic cells, but not in normal T, B and NK cells. ${ }^{12}$ Monocytes in peripheral blood might therefore be able to produce sCD86. We speculated that a reasonable starting point in the search for SCD86 expression would be in patients with asthma. To that end, we determined the concentrations of sCD86 in serum samples from patients with asthma and the correlations between sCD86 levels and clinical indices as well as the cell origin of sCD86.

\section{METHODS \\ Subjects}

The study protocol was approved by our institutional review board for human studies and informed consent was obtained from all subjects. Sixty eight asthmatic subjects were recruited consecutively from regular attenders in the pulmonary outpatient or emergency department at First Affiliated Hospital, Guangxi Medical University, PR China in the year from September 2001 to August 2002. The diagnosis and classification of the severity of asthma were based on the NHLBI/WHO Workshop on the Global Strategy for Asthma (GINA guidelines). ${ }^{13}$ The minimum criteria for the diagnosis of an asthma exacerbation included intense 
subjective breathlessness, audible wheezing on auscultation and a morning peak expiratory flow $<70 \%$ of the predicted value in the previous 3 months. Atopy was defined as a positive prick test to one or more common aeroallergens. Thirteen asthmatics were excluded from the study because they had been treated with oral and/or intravenous corticosteroids in the preceding 4 weeks, and three patients refused to participate in the study. Finally, 28 patients were recruited during a moderate to severe exacerbation either on their scheduled visit to the pulmonary outpatient department or during an emergency visit, and 24 patients with stable asthma were recruited on their scheduled visit if the symptoms and peak expiratory flow were stable with no change in treatment for at least 1 month. None of the studied patients with asthma smoked, had complications of other lung diseases, or had a history suggesting intolerance to nonsteroidal anti-inflammatory drugs. Twenty five non-smoking healthy volunteers were studied as controls. They had no history of atopic factors or allergic diseases, and no evidence of any lung diseases. Table 1 summarises the clinical characteristics and forced expiratory volume in l second $\left(\mathrm{FEV}_{1}\right.$, expressed as a percentage of the predicted value) of the patients on recruitment to the study.

\section{Assessment of airway responsiveness}

Baseline measurements of $\mathrm{FEV}_{1}$ were followed by methacholine challenge. Methacholine inhalation tests were carried out by the method described previously ${ }^{14}$ until a provocative concentration causing a $20 \%$ decrease in $\mathrm{FEV}_{1}\left(\mathrm{PC}_{20}-\mathrm{MCh}\right)$ was obtained.

\section{Blood samples}

Arterial blood samples were obtained from each subject for blood gas analysis to determine the oxygen and carbon dioxide tensions $\left(\mathrm{PaO}_{2}, \mathrm{PaCO}_{2}\right)$. Venous blood samples were collected either in ethylenediamine tetraacetic acid treated tubes for total and differential blood cell counts or untreated tubes to obtain serum for determining sCD86 concentrations, and the serum samples were stored at $-70^{\circ} \mathrm{C}$ before determination. Total cell counts were performed with a haemocytometer and different cell counts were made from blood smears stained with Diff-Quik Staining (Sigma). Cells were classified as lymphocytes, neutrophils, eosinophils, monocytes, and basophils as standard morphological criteria and absolute numbers of each cell type were calculated.

\section{Cell isolation and culture}

Heparinised venous blood was drawn from six healthy volunteers and six asthmatics during an acute exacerbation. Granulocytes and peripheral blood mononuclear cells (PBMCs) were isolated by centrifugation on Ficoll-Paque (Pharmacia, Uppsala, Sweden). The neutrophil layer was collected and the remaining erythrocytes removed by hypotonic lysis. Eosinophils were purified by negative immunomagnetic selection using a magnetically activated cell separator system (Miltenyi Biotec, Auburn, California, USA) as previously described. ${ }^{15}$ By negative selection, highly purified eosinophils, depleted of neutrophils (CDl6+ cells) and any contaminating mononuclear cells (CD3+/CD4+/ CD19+ cells), were routinely obtained. Untouched T cells, B cells, and monocytes from PBMCs were isolated by negative immunomagnetic selection using a Pan T cell isolation kit II, B cell isolation kit II, and monocyte isolation kit II, respectively (all purchased from Miltenyi Biotec), and all magnetic separation procedures were carried out according to the protocols provided by the manufacturer. The purities of $\mathrm{T}$ cells, B cells, neutrophils, eosinophils, or monocytes were all $>95 \%$. One million T cells, B cells, neutrophils, eosinophils, or monocytes alone were cultured in a volume of $1 \mathrm{ml}$ complete medium (RPMI 1640 supplemented with 5\% fetal calf serum and antibiotics reagent). After 24 hours the cellfree supernatants were collected and stored at $-70^{\circ} \mathrm{C}$ for determining sCD86 concentrations.

\section{Detection of sCD86}

The serum and supernatant samples previously stored at $-70^{\circ} \mathrm{C}$ were thawed and approximately $300 \mu \mathrm{l}$ of each sample were centrifuged for 10 minutes at $16000 \times g$ to remove any cell debris. The concentrations of sCD86 in serum samples and supernatants of cultured cells were measured by a sandwich enzyme-linked immunosorbent assay kit according to the manufacturer's protocol (Diaclone, Besançon, France). The minimum detectable dose of sCD86 was $0.6 \mathrm{U} / \mathrm{ml}$. All samples were assayed in duplicate.

\section{Statistical analysis}

Data were presented as mean (SE). Statistical analysis was done by one-way analysis of variance (ANOVA) for data conforming to a normal distribution, and by Friedman's test for those data with a non-parametric distribution (confirmed by the Shapiro-Will W test). The Student's $t$ test was used for comparison of two groups, and the Pearson or Spearman rank correlation was used to analyse correlations. A p value of $<0.05$ was considered statistically significant.

\section{RESULTS}

\section{Clinical characteristics}

Background data for the 25 normal control subjects, 28 patients with acute asthma exacerbations, and 24 with stable asthma enrolled in the study are shown in table 1 . The three groups did not differ significantly in age or sex (both $\mathrm{p}>0.05)$. There were no significant differences in atopic status or duration of asthma between patients with acute asthma exacerbations and those with stable asthma (both $\mathrm{p}>0.05)$. $\mathrm{FEV}_{1}$ in asthmatic subjects during an acute

Table 1 Characteristics of patients with asthma and control subjects

\begin{tabular}{|c|c|c|c|}
\hline & \multirow[b]{2}{*}{$\begin{array}{l}\text { Control subjects } \\
(n=25)\end{array}$} & \multicolumn{2}{|c|}{ Patients with asthma } \\
\hline & & $\begin{array}{l}\text { Stable } \\
(n=24)\end{array}$ & $\begin{array}{l}\text { Exacerbation } \\
(n=28)\end{array}$ \\
\hline$M / F$ & $14 / 11$ & $12 / 12$ & $13 / 15$ \\
\hline Age (years)* & $38.1(5.1)$ & $39.2(5.4)$ & $42.2(4.9)$ \\
\hline Asthma duration (years)* & - & $11.2(2.7)$ & $9.8(2.3)$ \\
\hline Atopic/non-atopic & $0 / 25$ & $17 / 7$ & $19 / 9$ \\
\hline $\mathrm{FEV}_{1}(\% \text { predicted })^{*}$ & - & $92.9(1.8)$ & $54.0(2.0) \dagger$ \\
\hline $\mathrm{PaO}_{2}(\mathrm{kPa})^{*}$ & - & $11.7(0.1)$ & $9.3(0.3) \dagger$ \\
\hline $\mathrm{PaCO}_{2}(\mathrm{kPa})^{*}$ & - & $5.3(0.1)$ & $4.4(0.1) \dagger$ \\
\hline
\end{tabular}




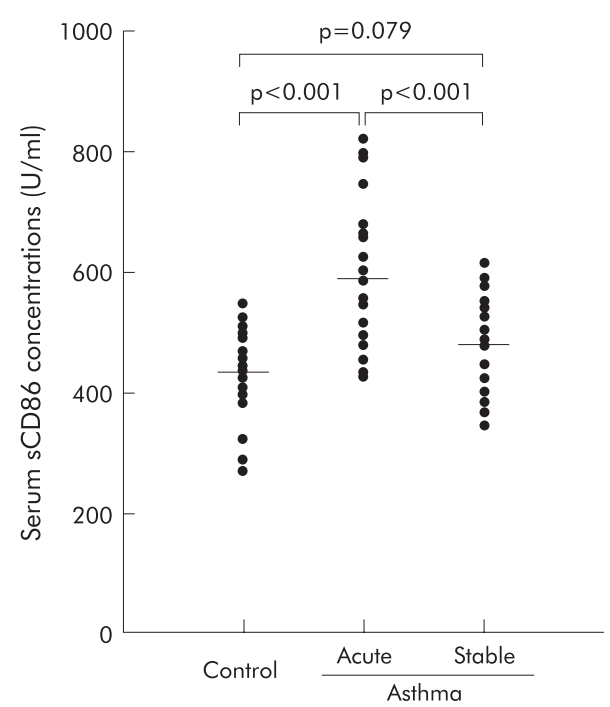

Figure 1 Comparison of serum concentrations of sCD86 in normal control subjects and asthmatic patients.

exacerbation decreased significantly compared with those with stable asthma and control subjects $(\mathrm{p}<0.001)$.

\section{Serum sCD86 levels in patients with asthma}

Figure 1 shows combined data of serum sCD86 concentrations from normal healthy volunteers, patients with acute asthma exacerbations, and those with stable asthma. sCD86 was detectable in all subjects studied. There was no obvious relationship between levels of sCD86 and the sex or age of the subjects. Serum samples from patients with acute asthma exacerbations had much higher levels of sCD86 (585.4 (20.5) U/ml (95\% confidence interval (CI) 543.4 to 627.4)) than serum from stable asthmatics (479.6 (15.7) U/ml (95\% CI 447.1 to 512.1) $\mathrm{p}<0.001$ ) and healthy individuals (435.1 (13.8) $\mathrm{U} / \mathrm{ml}(95 \%$ CI 406.6 to 463.6$) \mathrm{p}<0.001$ ), and there was no difference in serum sCD86 concentration between stable asthmatics and healthy individuals $(\mathrm{p}=0.079)$. In addition, the serum sCD86 concentration in 36 patients with atopic asthma (531.8 (17.7) U/ml (95\% CI 495.8 to 567.8) did not differ from that in 16 patients with non-atopic asthma (547.2 (28.8) $\mathrm{U} / \mathrm{ml}$ (95\% CI 485.9 to 608.5$), \mathrm{t}=0.469, \mathrm{p}=0.641$ ).

\section{Correlation between serum sCD86 levels and various clinical parameters}

Of 52 asthmatic patients, $\% \mathrm{FEV}_{1}$ was more than $60 \%$ in 38 and airway responsiveness was measured in 25 of these (20 atopic and five non-atopic asthmatics). The geometric mean (SE) $\mathrm{PC}_{20} \mathrm{MCh}$ was 0.89 (1.07) $\mathrm{mg} / \mathrm{ml}$. Details of $\% \mathrm{FEV}_{1}$, $\mathrm{PaO}_{2}$ and $\mathrm{PaCO}_{2}$ in the study subjects are shown in table 1. The serum sCD86 level was inversely correlated with $\mathrm{PC}_{20^{-}}$ MCh $(r=-0.498, \mathrm{p}=0.011), \% \mathrm{FEV}_{1}(r=-0.664$, $\mathrm{p}<0.001)$, and with $\mathrm{PaCO}_{2}(r=-0.659, \mathrm{p}<0.001$, fig 2$)$, but did not correlate with $\mathrm{PaO}_{2}(r=-0.321, \mathrm{p}=0.555)$. Total and differential blood cell counts in healthy controls and asthmatic subjects are shown in table 2. In 52 patients with asthma the serum sCD86 level was positively correlated with numbers of lymphocytes $(r=0.628, \mathrm{p}<0.001)$, eosinophils $(r=0.659, \mathrm{p}<0.001)$, or monocytes $(r=$ $0.729, \mathrm{p}<0.001)$ but not neutrophils $(r=-0.135, \mathrm{p}=0.339$; fig 3).

\section{Cell origin of $\mathrm{s} C D 86$}

To reveal the cell origin of sCD86, untouched T cells, B cells, neutrophils, eosinophils, and monocytes from peripheral blood were purified and cultured to determine the presence of sCD86 in the supernatants. No sCD86 could be detected in the supernatants of cultured T cells, B cells, neutrophils, or eosinophils from either asthmatic subjects or healthy volunteers. The most important finding was that monocytes
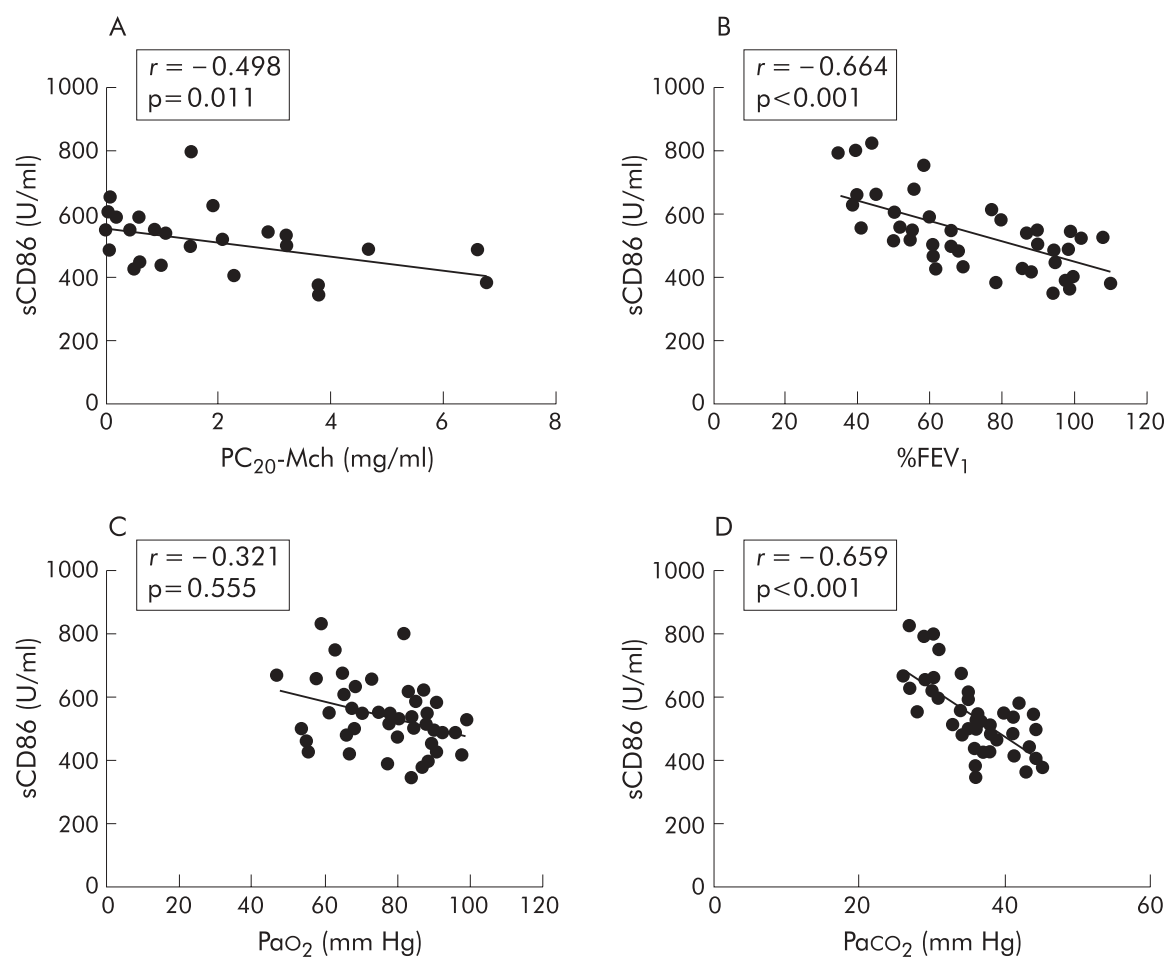

Figure 2 Correlation between concentrations of serum sCD86 and (A) PC $20-M C h(n=25),(B) \% F E V_{1}(n=52),(C) P a O_{2}(n=52)$, and (D) PacO 2 $(\mathrm{n}=52)$ in patients with asthma. 

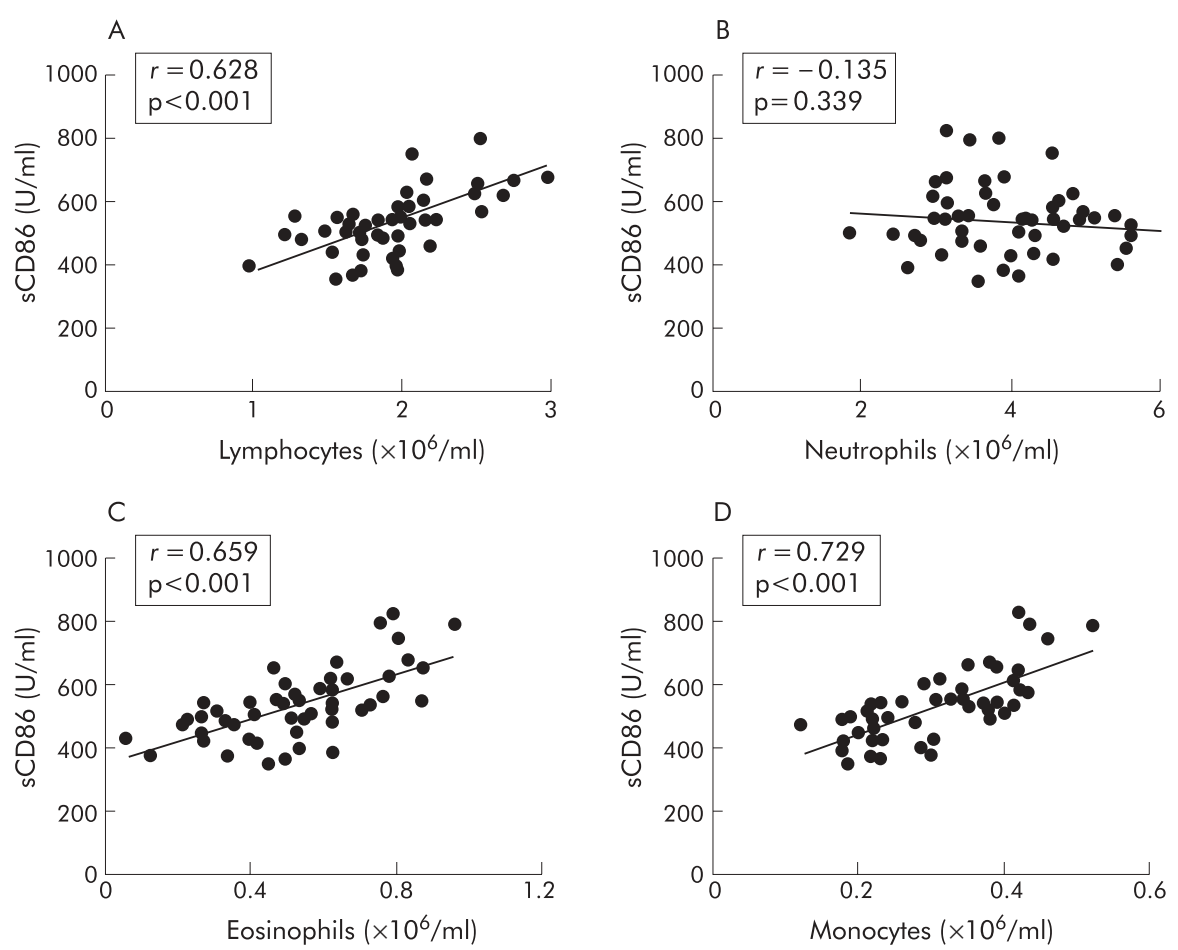

Figure 3 Correlation between concentrations of serum sCD86 and numbers of (A) lymphocytes, (B) neutrophils, (C) eosinophils, and (D) monocytes in peripheral blood of 52 patients with asthma.

were the only cell type which released sCD86 into the culture supernatants, and that monocytes from asthmatic subjects produced more sCD86 than those from healthy volunteers (fig 4).

\section{DISCUSSION}

We have shown that sCD86 is detected in the serum of healthy controls and both atopic and non-atopic asthmatic subjects, and that sCD86 levels are raised in the serum of patients with acute asthma exacerbations. The concentration of serum sCD86 in asthmatic patients was inversely correlated with $\mathrm{PC}_{20}-\mathrm{MCh}, \% \mathrm{FEV}_{1}$, and $\mathrm{PaCO}_{2}$. These findings suggest a potentially important role for SCD86 in asthma. To our knowledge, this study is the first to suggest the possible clinical significance of SCD86 in human asthma.

Co-stimulation through the B7/CD28 pathway plays a critical role in the establishment of antigen driven immune responses. ${ }^{16}$ Hofer and coworkers ${ }^{17}$ found that atopic patients with asthma who were exposed to allergens had significantly higher levels of CD86 expression on B cells than atopic asthmatic subjects not exposed to allergen in vivo or nonatopic controls. In contrast, there were no differences in

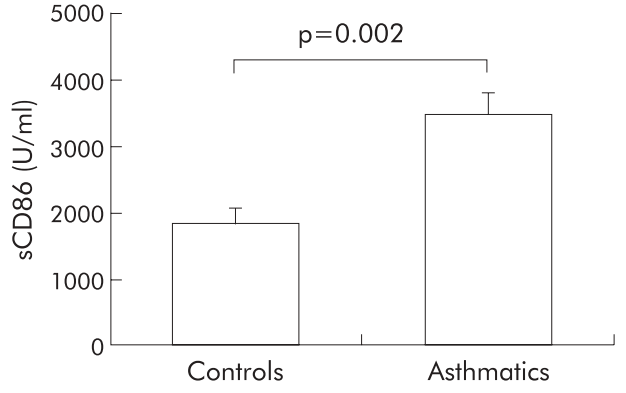

Figure $4 \mathrm{sCD} 86$ production by non-activated monocytes in vitro. One million monocytes from six normal control subjects and six asthmatic subjects with an exacerbation were purified and cultured in a volume of $1 \mathrm{ml}$ for 24 hours and the supernatants were collected for determination of sCD86 concentrations.

CD80 expression among the three study groups. When PBMCs from asthmatic patients or normal control subjects were stimulated with IL- 4 or IL-13, the expression of CD86 (but not CD80) was significantly increased on B cells. ${ }^{17}$ It has been shown that blocking CD86 but not CD80 co-stimulation

Table 2 Mean (SE) white blood cell counts and differential counts in asthmatic and control subjects

\begin{tabular}{llll}
\hline & & \multicolumn{2}{l}{ Patients with asthma } \\
\cline { 3 - 4 } & $\begin{array}{lll}\text { Control subjects } \\
(\mathbf{n}=\mathbf{2 5})\end{array}$ & $\begin{array}{l}\text { Stable } \\
(\mathbf{n}=\mathbf{2 4})\end{array}$ & $\begin{array}{l}\text { Exacerbation } \\
(\mathbf{n}=\mathbf{2 8})\end{array}$ \\
\hline Total cell count $\left(\times 10^{6} / \mathrm{ml}\right)$ & $6.08(0.28)$ & $6.82(0.22)^{*}$ & $6.74(0.20)^{*}$ \\
Lymphocytes $\left(\times 10^{6} / \mathrm{ml}\right)$ & $1.57(0.11)$ & $1.87(0.06)^{*}$ & $2.03(0.09)^{*}$ \\
Neutrophils $\left(\times 10^{6} / \mathrm{ml}\right)$ & $3.94(0.22)$ & $4.08(0.21)$ & $3.91(0.16)$ \\
Eosinophils $\left(\times 10^{6} / \mathrm{ml}\right)$ & $0.21(0.03)$ & $0.48(0.04)^{*}$ & $0.56(0.04)^{*}$ \\
Monocytes $\left(\times 10^{6} / \mathrm{ml}\right)$ & $0.30(0.02)$ & $0.29(0.02)$ & $0.32(0.02)$ \\
\hline${ }^{*} \mathrm{p}<0.05$ compared with control subjects. & & \\
\hline
\end{tabular}


is effective in inhibiting allergic responses and that these effects are associated with reduced Th2 cytokine production. $^{18}{ }^{19}$ Tsuyuki and coworkers ${ }^{20}$ have also reported that airway allergen challenge upregulates the expression of CD86 on B cells from the lung and airway administration of antiCD86 monoclonal antibody inhibits local IgE production in a mouse model of asthma. In addition, blockade of costimulation with CTLA4-Ig (a fusion protein known to prevent co-stimulation by blocking CD28/B7 interactions) inhibits airway hyperresponsiveness, inflammatory cell infiltration, and allergen-specific responsiveness of thoracic $\mathrm{T}$ cells in a murine model of asthma. ${ }^{21} \mathrm{CD} 28$-deficient mice did not manifest airway inflammation in response to allergen challenge, despite evidence of systemic sensitisation, and this was due to a failure in T cell recruitment and defective Th2 cell development. ${ }^{22}$ Prevention of CTLA-4 engagement by blockade of CD86 in CD28-deficient mice restored lymphocyte recruitment to the airway but did not result in tissue eosinophilia, Ig isotype switching, or Th2 cytokine secretion. ${ }^{22}$ All the abovementioned data support the hypothesis that CD86 is an important co-stimulatory molecule in the pathogenesis of allergic asthma.

Numerous studies have shown that soluble forms of B7 molecules have potent functional activity and that, depending on the experimental system used, can either inhibit or enhance immune responses. ${ }^{1123} 24$ SCD86 might play an important role in immune regulation by binding with the CD28 molecules, thus interfering with the binding of CD28 and/or CTLA-4. Recombinant SCD86 at high concentrations in vitro could inhibit mixed leucocyte reactions and cellular proliferation, ${ }^{25}$ probably by interference with CD28 signalling. sCD86 might also interfere with CD28-B7 interactions and block negative signals transmitted via surface bound CD86. It has been reported that sCD86 results from an alternatively spliced transcript (CD86deltaTM) characterised by deletion of the transmembrane domain. ${ }^{11}$ Recombinant CD86deltaTM binds to CD28 and CTLA-4 and induces the activation of T cells after stimulation with anti-CD3 monoclonal antibody. CD86deltaTM also induces interferon- $\gamma$ production by virus specific CD8+ memory human T cells stimulated with the Flu Ml peptide. ${ }^{11}$ sCD86 molecule therefore appears to be a functional co-stimulatory molecule playing a potentially important role in immune surveillance. The high levels of sCD86 in serum samples from asthmatic subjects with acute exacerbations may play a protective role via interference with the CD28-B7 interaction or, alternatively, contribute to disease manifestations by interference with the CD28-B7 interaction.

Membrane CD86 is expressed predominantly on monocytes, dendritic cells, lymphocytes, eosinophils, and neutrophils. ${ }^{11}{ }^{26-29}$ It has been found that the transcript for SCD86 is expressed in normal monocytes and dendritic cells. ${ }^{12}$ Our results showed that the serum sCD86 level was positively correlated with numbers of lymphocytes, eosinophils, and monocytes, but not neutrophils. These results suggest that sCD86 detected in asthmatic serum might derive from lymphocytes, eosinophils, and monocytes. However, our in vitro experimental results showed that cultured $\mathrm{T}$ cells, $\mathrm{B}$ cells, neutrophils, or eosinophils from either asthmatics or healthy volunteers did not produce detectable sCD86. In contrast, without any stimulation, monocytes were capable of releasing SCD86 into the culture supernatants. We also noted that monocytes from asthmatics produced more sCD86 than those from healthy volunteers. We therefore infer that serum sCD86 is derived from monocytes in peripheral blood and that monocytes are further responsible for the increase in serum sCD86 in asthmatic patients with acute exacerbations. On the other hand, we cannot rule out the possibility that other types of leucocytes such as lymphocytes and eosinophils are also able to produce sCD86 in vivo under asthmatic conditions.

In summary, our results show that the serum sCD86 protein level is significantly increased in asthmatic patients during an exacerbation and that this level correlates with the severity of asthma. Our results also suggest that sCD86 is probably derived from monocytes in the peripheral blood. Further elucidation of the roles and functions of sCD86 in bronchial asthma will require longitudinal studies and detailed molecular research, comparing the immunopathological characteristics of asthma in diverse clinical settings using samples of induced sputum, bronchoalveolar lavage fluid, or bronchial biopsy specimens.

\section{ACKNOWLEDGEMENTS}

The authors thank Miss Jian Li for her skilful technical assistance, and Feng Gao for helpful discussions and critical review of the manuscript.

\section{Authors' affiliations}

H-Z Shi, Z-F Xie, J-M Deng, Y-Q Chen, C-Q Xiao, Departments of Respiratory and Critical Care Medicine, First Affiliated Hospital, Guangxi Medical University, Nanning 530021, Guangxi, People's Republic of China

This study was supported in part by research grant no 30060079 from the National Natural Science Foundation of China, in part by research grant no 200260 from the Ministry of Education, People's Republic of China, and in part by research grant no 200203 from the Bureau of Health, Guangxi Zhuang Autonomous Zone, People's Republic of China.

\section{REFERENCES}

1 Chambers CA, Allison JP. Co-stimulation in T cell responses. Curr Opin Immunol 1997;9:396-404.

2 Greenfield EA, Nguyen KA, Kuchroo VK. CD28/B7 costimulation: a review. Crit Rev Immunol 1998;18:389-418.

3 Linsley PS, Clark EA, Ledbetter JA. T-cell antigen CD28 mediates adhesion with $B$ cells by interacting with activation antigen B7/BB-1. Proc Natl Acad Sci USA 1990;87:5031-5.

4 Freeman GJ, Gribben JG, Boussiotis VA, et al. Cloning of B7-2: a CTLA-4 counter-receptor that costimulates human T cell proliferation. Science 1993;262:909-11.

5 van der Merwe PA, Bodian DL, Daenke S, et al. CD80 (B7-1) binds both CD28 and CTLA-4 with a low affinity and very fast kinetics. J Exp Med 1997; 185:393-403.

6 Ikemizu S, Gilbert RJ, Fennelly JA, et al. Structure and dimerization of a soluble form of B7-1. Immunity 2000;12:51-60.

7 Matulonis U, Dosiou C, Freeman G, et al. B7-1 is superior to B7-2 costimulation in the induction and maintenance of $\mathrm{T}$ cell-mediated antileukemia immunity. Further evidence that B7-1 and B7-2 are functionally distinct. J Immunol 1996;156:1126-31.

8 Kuchroo VK, Das MP, Brown JA, et al. B7-1 and B7-2 costimulatory molecules activate differentially the Th1/Th2 developmental pathways: application to autoimmune disease therapy. Cell 1995;80:707-18.

9 Mazzarella G, Bianco A, Catena E, et al. Th1/Th2 lymphocyte polarization in asthma. Allergy 2000;55(Suppl 61):6-9.

10 Schweitzer AN, Sharpe AH. The complexity of the B7-CD28/CTLA-4 costimulatory pathway. Agents Actions Suppl 1998;49:33-43.

11 Jeannin P, Magistrelli G, Aubry JP, et al. Soluble CD86 is a costimulatory molecule for human T lymphocytes. Immunity 2000;13:303-12.

12 Hock BD, Patton WN, Budhia S, et al. Human plasma contains a soluble form of CD86 which is present at elevated levels in some leukemia patients. Leukemia 2002;16:865-73.

13 NHLBI/WHO Workshop Report. Global strategy for asthma management and prevention. Publication no 02-3659. Bethesda, MD: National Heart, Lung, and Blood Institute, 2002.

14 Hargreave FE, Ryan G, Thomson NC, et al. Bronchial responsiveness to histamine or methacholine in asthma: measurement and clinical significance. J Allergy Clin Immunol 1981;68:347-55.

15 Shi HZ, Humbles A, Gerard C, et al. Lymph node trafficking and antigen presentation by endobronchial eosinophils. J Clin Invest 2000;105:945-53.

16 Lenschow DJ, Walunas TL, Bluestone JA. CD28/B7 system of T cell costimulation. Annu Rev Immunol 1996;14:233-58.

17 Hofer MF, Jirapongsananuruk O, Trumble AE, et al. Upregulation of B7.2, but not B7.1, on B cells from patients with allergic asthma. J Allergy Clin Immunol 1998;101:96-102.

18 Keane-Myers AM, Gause WC, Finkelman FD, et al. Development of murine allergic asthma is dependent upon B7-2 costimulation. J Immunol 1998; 160:1036-43. 
19 Haczku A, Takeda K, Redai I, et al. Anti-CD86 (B7.2) treatment abolishes allergic airway hyperresponsiveness in mice. Am J Respir Crit Care Med 1999; 159:1638-43

20 Tsuyuki S, Tsuyuki J, Einsle K, et al. Costimulation through B7.2 (CD86) is required for the induction of a lung mucosal T helper cell 2 (Th2) immune response and altered airway hyperresponsiveness. J Exp Med 1997;185:1671-9.

21 Krinzman SJ, De Sanctis GT, Cernadas M, et al. Inhibition of T cell costimulation abrogates airway hyperresponsiveness in a murine model. J Clin Invest 1996:98:2693-9.

22 Burr JS, Kimzey SL, Randolph DR, et al. CD28 and CTLA4 coordinately regulate airway inflammatory cell recruitment and T-helper cell differentiation after inhaled allergen. Am J Respir Cell Mol Biol 2001;24:563-8.

23 Rennert $P$, Furlong $K$, Jellis $C$, et al. The lgV domain of human B7-2 (CD86) is sufficient to co-stimulate T lymphocytes and induce cytokine secretion. Int Immunol 1997:9:805-13.
24 Flo J, Tisminetzky S, Baralle F. Codelivery of DNA coding for the soluble form of CD86 results in the down-regulation of the immune response to DNA vaccines. Cell Immunol 2001;209:120-31.

25 Oaks MK, Hallett KM, Penwell RT, et al. A native soluble form of CTLA-4. Cell Immunol 2000;201:144-53.

26 Buelens C, Willems F, Delvaux A, et al. Interleukin-10 differentially regulates B7-1 (CD80) and B7-2 (CD86) expression on human peripheral blood dendritic cells. Eur J Immunol 1995;25:2668-72.

27 Elliott SR, Macardle PJ, Roberton DM, et al. Expression of the costimulatory molecules, CD80, CD86, CD28, and CD152 on lymphocytes from neonates and young children. Hum Immunol 1999;60:1039-48.

28 Celestin J, Rotschke O, Falk K, et al. IL-3 induces B7.2 (CD86) expression and costimulatory activity in human eosinophils. J Immunol 2001; 167:6097-104.

29 lking-Konert C, Vogt S, Radsak M, et al. Polymorphonuclear neutrophils in Wegener's granulomatosis acquire characteristics of antigen presenting cells. Kidney Int 2001;60:2247-62.

\section{LUNG ALERT}

Sensitivity of pulmonary function tests in assessing whether bronchodilatation is different in healthy subjects and asthmatics

$\Delta$ Houghton CM, Woodcock AA, Singh D. A comparison of lung function methods for assessing dose-response effects of salbutamol. Br J Clin Pharmacol 2004;58:134-41

T he ability of different pulmonary function tests to detect dose-response effects depends on both the variability and sensitivity of the methods used. In clinical trials bronchodilatation is usually assessed by spirometry. Body plethysmography and impulse oscillation (IOS) are alternative techniques. The advantage of IOS is that it is simpler to perform and requires minimal effort from the subject. It can also measure different components of respiratory impedance, including both central and peripheral airways resistance.

The authors of this paper compared the sensitivity and variability of the above pulmonary function methods to measure the dose-response effects of salbutamol in both healthy subjects and asthmatics. The study involved 12 healthy subjects, 12 with mild asthma ( $\mathrm{FEV}_{1}$ $>80 \%$ predicted), and 12 with moderate asthma ( $\mathrm{FEV}_{1}<80 \%$ predicted). Pulmonary function was measured by all three methods on day 1 and repeated after 30 minutes to assess variability. One week later the measurements were repeated at the same time of day, after which increasing doses of nebulised salbutamol were administered and pulmonary function was recorded after each dose. The most sensitive measurements were spirometry in healthy individuals and plethysmography in those with mild asthma. All three pulmonary function methods showed similar sensitivity in individuals with moderate asthma. However, spirometry showed the least variability of the tests. The sensitivities of the tests also varied with the degree of airflow obstruction.

This study suggests that the airways of healthy subjects respond differently from those of asthmatic subjects. In clinical trials the results of dose-response curves in healthy individuals are not necessarily applicable to those with asthma. This needs to be taken into account when choosing the most appropriate test to measure pulmonary function.

M Menon

Specialist Registrar, Department of Respiratory Medicine, Homerton University Hospital, London, UK; mkmenon@doctors.org.uk 